\title{
Association of endothelial and glycocalyx injury biomarkers with fluid administration, development of acute kidney injury, and 90-day mortality: data from the FINNAKI observational study
}

Nina Inkinen ${ }^{1,2^{*}} \mathbb{D}$, Ville Pettilä2 ${ }^{2}$, Päivi Lakkisto ${ }^{3,4}$, Anne Kuitunen ${ }^{5}$, Sakari Jukarainen², Stepani Bendel ${ }^{6}$, Outi Inkinen ${ }^{7}$, Tero Ala-Kokko ${ }^{8}$, Suvi T. Vaara ${ }^{2,9}$ and the FINNAKI Study Group

\begin{abstract}
Background: Injury to endothelium and glycocalyx predisposes to vascular leak, which may subsequently lead to increased fluid requirements and worse outcomes. In this post hoc study of the prospective multicenter observational Finnish Acute Kidney Injury (FINNAKI) cohort study conducted in 17 Finnish intensive care units, we studied the association of Syndecan-1 (SDC-1), Angiopoetin-2 (Ang-2), soluble thrombomodulin (STM), vascular adhesion protein-1 (VAP-1) and interleukin-6 (IL-6) with fluid administration and balance among septic critical care patients and their association with development of acute kidney injury (AKI) and 90-day mortality.

Results: SDC-1, Ang-2, STM, VAP-1 and IL-6 levels were measured at ICU admission from 619 patients with sepsis. VAP-1 decreased $(p<0.001)$ and IL-6 increased $(p<0.001)$ with increasing amounts of administered fluid, but other biomarkers did not show differences according to fluid administration. In linear regression models adjusted for IL-6, only VAP-1 was significantly associated with fluid administration on day $1(p<0.001)$ and the cumulative fluid balance on day $5 / \mathrm{ICU}$ discharge $(p=0.001)$. Of 415 patients admitted without AKI, altogether 112 patients $(27.0 \%)$ developed $A K I>12 \mathrm{~h}$ from ICU admission $\left(\mathrm{AKI}_{>12 \mathrm{~h}}\right.$ ). They had higher sTM levels than patients without AKI, and after multivariable adjustment log, sTM level was associated with $\mathrm{AKI}_{>12 \mathrm{~h}}$ with $\mathrm{OR}(95 \% \mathrm{Cl})$ of 12.71 (2.96-54.67), $\left.p=0.001\right)$. Ninety-day non-survivors $(n=180 ; 29.1 \%$ ) had higher SDC-1 and STM levels compared to survivors. After adjustment for known confounders, log SDC-1 (OR [95\% CI] 2.13 [1.31-3.49], $p=0.002)$, log STM (OR [95\% CI] 7.35 [2.29-23.57], $p<0.001)$, and log Ang-2 (OR [95\% Cl] 2.47 [1.44-4.14], $p=0.001)$ associated with an increased risk for 90-day mortality. Finally, patients who had high levels of all three markers, namely, SDC-1, Ang-2 and STM, had an adjusted OR of 5.61 (95\% Cl 2.67-11.79; $p<0.001$ ) for 90-day mortality.
\end{abstract}

Conclusions: VAP-1 and IL-6 associated with fluid administration on the first ICU day. After adjusting for confounders, sTM was associated with development of AKI after $12 \mathrm{~h}$ from ICU admission. SDC-1, Ang-2 and sTM were independently associated with an increased risk for 90-day mortality.

Keywords: Biomarker, Glycocalyx, Sepsis, Fluid balance, Fluid resuscitation, Soluble thrombomodulin, Acute kidney injury

\footnotetext{
${ }^{*}$ Correspondence: nina.inkinen@ksshp.fi

${ }^{1}$ Department of Anesthesia and Intensive Care, Central Finland Central Hospital, Central Finland Health Care District, Keskussairaalantie 19 M rak 2 krs, 40620 Jyväskylä, Finland

Full list of author information is available at the end of the article
} 


\section{Background}

Endothelial cells line the luminal side of all blood vessels. Glycocalyx is located on the top of the endothelium. It is a thin (few dozens of nanometers), complex layer with a framework consisting of glycoproteins and proteoglycans between the endothelial cell wall and flowing blood [1, 2]. It plays a key role in regulation of vascular permeability and blood cell-vessel interactions [1-3]. In critical illness, the body responds to stress by initiating sympathoadrenal activation, which leads to the release of inflammatory mediators, such as interleukin-6 (IL-6), and damage to the endothelium and glycocalyx, resulting in increased vascular permeability [4-6]. Several plasma biomarkers may be measured as indicators of glycocalyx $[4,7,8]$ and endothelial injury [7-11].

We hypothesized that higher plasma levels of endothelial and glycocalyx biomarkers measured at intensive care unit (ICU) admission would indicate more severe endothelial and glycocalyx injury, more severe capillary leakage, and subsequently, higher amounts of administered fluid. Therefore, we primarily studied the association between glycocalyx (Syndecan-1; SDC-1) and endothelial injury biomarkers (Angiopoietin-2; Ang-2, soluble thrombomodulin; sTM, and vascular adhesion protein-1; VAP-1) and cytokine IL-6 (as marker of the severity of inflammation) and fluid administration among critically ill septic patients. Second, we aimed to study the association of these markers with acute kidney injury (AKI) and 90-day mortality.

\section{Methods}

This was a post hoc laboratory study of the prospective multicenter observational Finnish Acute Kidney Injury (FINNAKI) cohort study conducted in 17 Finnish intensive care units in 2011-2012 [12]. The Ethics Committee of the Department of Surgery at the Helsinki University Hospital gave nationwide approval for the study (reference number: 18/13/03/02/2010) and accepted the use of deferred consent from the patient or next of kin with written informed consent obtained as soon as possible. The Finnish National Institute of Health and Welfare allowed data collection from medical records of deceased patients to avoid bias in the primary endpoint of the FINNAKI study (incidence and outcome of AKI). The current laboratory study includes only patients who or whose next of kin gave a written informed consent.

The FINNAKI study enrolled all adult emergency ICU admissions to study ICUs of any length and elective postoperative patients with an expected ICU stay longer than $24 \mathrm{~h}$ [12]. Exclusion criteria are presented in Additional file 1: Methods section of the 1.2, page 6 . The current study included all FINNAKI study patients who were septic at ICU admission, had fluid balance data available for day 1, and a blood sample taken at ICU admission. FINNAKI study was observational and did not include fluid management protocol. Thus, all patients were treated according to the judgement of the treating clinician and the Surviving Sepsis Guidelines in place at that time [13].

\section{Data collection}

We collected data on baseline chronic illnesses, ICU diagnoses, severity scores, and ICU treatment. Please see details in Additional file 1: 1.3, page 6.

\section{Definitions}

We defined sepsis according to the American College of Chest Physicians/Society of Critical Care Medicine (ACCP/SCCM) definition [14]. Presence of AKI according to Kidney Disease: Improving Global Outcomes (KDIGO) criteria [15] considering creatinine (measured daily), hourly urine output, and use of renal replacement therapy (RRT) was screened until day 5 in the ICU. As a baseline creatinine, we used the most recent value from the previous year excluding the week preceding ICU admission according to the KDIGO guideline [15] and if it was not available, we estimated it using the modification of diet in renal disease (MDRD) equation assuming a GFR of $75 \mathrm{~mL} / \mathrm{min} / 1.73 \mathrm{~m}^{2}$ [16].

\section{Outcomes}

Our primary outcome was association of SDC-1, Ang-2, sTM, VAP-1 and IL-6 with (a) fluid administration per hour within the first ICU day and (b) cumulative balance at ICU discharge or on day 5 whichever came first. Secondarily, we evaluated the independent associations of these biomarkers with development of AKI and 90-day mortality. From the AKI analysis, we excluded patients who were admitted with AKI (defined as AKI diagnosis made within $12 \mathrm{~h}$ of ICU admission) to study the temporal association of biomarkers and development of AKI [17].

\section{Calculation of fluid administration and balance}

We prospectively collected data of the total amount of fluids administered to the patient daily including maintenance and resuscitation fluids, nutrition, blood products, drug infusions, and correspondingly, data about total fluid output (urine output, drainage fluids, bleeding, losses from gastrointestinal tract). A surrogate for evaporation (generally, $1000 \mathrm{~mL}$ daily for normothermic patients and additionally, an addition for each Celcius degree of fever per hour) was included in the fluid losses according to clinical practice. Fluid losses were subtracted from administered fluid to calculate fluid balance. The fluid data were collected from the ICU electronic patient records according to local ICUs fluid 
charting day. In most ICUs, the fluid charting day was a 24-h period starting from noon. Thus, the first study day was not a 24-h period for most of the patients (for example, if patient was admitted 8 p.m., the first fluid day was until next noon, altogether $16 \mathrm{~h}$ ). Therefore, the duration of fluid administration and balance data collected for that day varied between 1 and $24 \mathrm{~h}$. In the current analysis, we combined short fluid charting days (less than $2 \mathrm{~h}$ ) to the administration and balance data of the subsequent day 1 , and report here the administered fluid and balance normalized then to the total duration of fluid charting day that was between 2 and $26 \mathrm{~h}$. Examples of these calculations are presented in Additional file 1: 1.4 page 7.

As an additional sensitivity analysis, fluid administration data from 44 patients from Helsinki University Hospital ICU were retrospectively extracted in 12-h blocks from the ICU data management system and were found to correlate well (rho 0.91, $p<0.001$ ) with the day 0 administrations normalized to the duration of day 0 observation period.

Cumulative balance at ICU discharge or on day 5 (last data collection day) was normalized to patient weight at ICU admission and reported as a percentage.

\section{Laboratory samples and analyses}

Plasma samples were collected at ICU admission $(0 \mathrm{~h})$ in lithium-heparin tubes, centrifuged, aliquoted, and frozen in $-80{ }^{\circ} \mathrm{C}$ until analyzed between April and October in 2017. To assess the temporal behavior of the markers, we analyzed sequential samples from 44 patients from Helsinki University Hospital ICU taken every 12 h until 36 h (40 patients had full series of samples from 0 to $36 \mathrm{~h}$ ). Details of the laboratory analyses are presented in Additional file $1: 1.5$ page 8 .

\section{Statistical analyses}

We report patients' baseline characteristics using counts and percentages for categorical variables and medians with interquartile ranges (IQR) for continuous variables as data were non-normally distributed. To assess possible differences in patients grouped according to fluid input, AKI status, or survival, we compared continuous data using the Mann-Whitney $U$ or Kruskal-Wallis tests and categorical data using the Fisher's exact or Chi-squared tests, as appropriate.

We ran multivariable linear regression models examining the association between different biomarkers and fluid input or cumulative balance, controlling for the effect of interleukin-6. All biomarkers and fluid input on day 0 normalized to hours were $\log$ transformed. Three subjects were removed from the analyses due to having high influence (Cook's Distance of over $4 /(n-p-1)$, where $\mathrm{n}$ is the number of subjects and $p$ is the number of covariates). We compared sequential biomarker measurements from same patients with Friedman's test.

We used multivariable logistic regression models, according to general practice concerning predictive models in critical care [18], to study whether biomarker levels were independently associated with the development of AKI after $12 \mathrm{~h}$ from admission $\left(\mathrm{AKI}_{>12 \mathrm{~h}}\right)$ and 90-day mortality. We studied the effect of possible confounders (as listed in Table 1) in univariate models for development of AKI and 90-day mortality. We included all variables with a univariate $p$ value less than 0.20 in multivariable models, however excluding variables that were clinically closely related (such as severity scores). Additionally, we adjusted for sex, as recommended [19]. Please see Additional file 1: 1.6 (page 8) about handling of missing data in regression models. Model fit was assessed with Hosmer-Lemeshow statistics.

To study whether a combination of biomarkers could identify a group of patients with especially high risk for $\mathrm{AKI}_{>12 \mathrm{~h}}$ and 90-day mortality [20], we built biomarker summary score that comprised biomarkers that were associated with the development of AKI and/or 90-day mortality in univariate models with $p$ values less than 0.20 [21]. We categorized the biomarker levels into tertiles, and for each patient, calculated the total number of biomarkers (up to three) where the patient fell into the highest tertile. Next, we studied unadjusted and adjusted associations of the biomarker summary score with $\mathrm{AKI}_{>12 \mathrm{~h}}$ and 90 -day mortality with logistic regression.

We set the significance level to $1 \%$ and considered $p$ values $<0.01$ as statistically significant. We conducted analyses with SPSS statistics 24 for Windows and SPSS 23 for Mac.

\section{Results}

\section{Patients}

We included 619 patients admitted to the ICU with sepsis or septic shock (Additional file 1: Figure S1). Altogether, 137 (22.1\%) patients were admitted from operating room or postoperative intermediate care unit, 225 (36.3\%) from emergency department, 197 (31.8\%) from the wards and 60 (9.7\%) from another ICU or intermediate care unit. The most common origins of sepsis were lungs in 296 (47.8\%) and gastrointestinal tract in $156(25.2 \%)$ patients (Table 1). Biomarker levels at ICU admission according to the presence of baseline chronic illnesses are presented in Additional file 1: 2.1, page 10 and Table S1.

\section{Fluid administration, balance and biomarker levels}

During the first ICU day, the patients received a median of $247 \mathrm{~mL} / \mathrm{h}$ (IQR [173-363] $\mathrm{mL} / \mathrm{h}$ ) fluids. Divided into tertiles according to fluid administration, less than $201 \mathrm{~mL} / \mathrm{h}$ fluid was administered in the 1st tertile, 
Table 1 Patient characteristics

\begin{tabular}{|c|c|c|c|c|c|}
\hline & Data available & All patients, $n=619$ & $\begin{array}{l}\text { 90d survivors, } \\
n=439 \text { (70.9\%) }\end{array}$ & $\begin{array}{l}\text { Non-survivors, } \\
n=180 \text { (29.1\%) }\end{array}$ & $p$ value \\
\hline Age (years) & 619 & $66[55$ to 75$]$ & $62[52$ to 73$]$ & 73 [62 to 80$]$ & $<0.001$ \\
\hline Sex; female & 619 & $223(36.0 \%)$ & $154(35.1 \%)$ & $69(38.3 \%)$ & 0.462 \\
\hline Body mass index $\left(\mathrm{kg} / \mathrm{m}^{2}\right)$ & 618 & $26.8[23.6$ to 30.1$]$ & 27.4 [24.1 to 30.9$]$ & 25.4 [23.0 to 27.9$]$ & $<0.001$ \\
\hline \multicolumn{6}{|l|}{ Comorbidities } \\
\hline Hypertension & 616 & $329(53.2 \%)$ & $229(52.4 \%)$ & $100(55.9 \%)$ & 0.477 \\
\hline Coronary artery disease or ASO & 609 & $89(14.4 \%)$ & $55(12.7 \%)$ & $34(19.3 \%)$ & 0.043 \\
\hline Chronic heart failure & 613 & $71(11.5 \%)$ & $38(8.7 \%)$ & $33(18.5 \%)$ & 0.001 \\
\hline COPD & 612 & $79(12.8 \%)$ & $56(12.9 \%)$ & $23(12.9 \%)$ & $>0.999$ \\
\hline Chronic kidney disease (GFR < $\left.60 \mathrm{~mL} / \mathrm{min} / 1.73 \mathrm{~m}^{2}\right)$ & 615 & $42(6.8 \%)$ & $23(5.3 \%)$ & $19(10.7 \%)$ & 0.021 \\
\hline Diabetes & 619 & $158(25.5 \%)$ & $121(27.6 \%)$ & $37(20.6 \%)$ & 0.084 \\
\hline Baseline creatinine $(\mu \mathrm{mol} / \mathrm{L})$ & 436 & 76 [61 to 92] & 76 [61 to 91] & 76 [62 to 98] & 0.458 \\
\hline Pre-ICU chronic corticosteroid use & 615 & $77(12.4 \%)$ & $41(9.3 \%)$ & $36(20.0 \%)$ & $<0.001$ \\
\hline Pre-ICU immunosuppression & 614 & $56(9.0 \%)$ & $36(8.2 \%)$ & $20(11.1 \%)$ & 0.279 \\
\hline Pre-ICU radiocontrast & 616 & $122(19.7 \%)$ & $93(21.2 \%)$ & $29(16.1 \%)$ & 0.150 \\
\hline Pre-ICU aminoglycoside & 618 & $7(1.1 \%)$ & $2(0.5 \%)$ & $5(2.8 \%)$ & 0.013 \\
\hline Pre-ICU NSAID & 582 & $94(15.2 \%)$ & $69(15.7 \%)$ & $25(13.9 \%)$ & 0.621 \\
\hline Pre-ICU amphotericin B & 616 & $3(0.5 \%)$ & $0[0.0 \%)$ & $3(1.7 \%)$ & 0.024 \\
\hline Surgical admission & 619 & $149(24.1 \%)$ & $115(26.2 \%)$ & $34(18.9 \%)$ & 0.062 \\
\hline \multicolumn{6}{|l|}{ Infection source } \\
\hline CNS & 619 & $18(2.9 \%)$ & $16(3.6 \%)$ & $2(1.1 \%)$ & 0.114 \\
\hline Lung & 619 & $296(47.8 \%)$ & $209(47.6 \%)$ & $87(48.3 \%)$ & 0.929 \\
\hline Gl tract & 619 & $156(25.2 \%)$ & $108(24.6 \%)$ & $48(26.7 \%)$ & 0.611 \\
\hline Urinary tract & 619 & $46(7.4 \%)$ & $34(7.7 \%)$ & $12(6.7 \%)$ & 0.737 \\
\hline Skin and soft tissue & 619 & $55(8.9 \%)$ & $45(10.3 \%)$ & $10(5.6 \%)$ & 0.064 \\
\hline Other & 619 & $19(3.1 \%)$ & $10(2.3 \%)$ & $9(5.0 \%)$ & 0.12 \\
\hline Time from hospital admission to ICU admission (h) & 618 & 22 [9 to 59$]$ & $21[8$ to 53$]$ & $23[11$ to 74$]$ & 0.067 \\
\hline First lactate $(\mathrm{mmol} / \mathrm{L})^{\mathrm{a}}$ & 536 & $1.80[1.10$ to 3.31$]$ & $1.60[1.00$ to 2.87$]$ & $2.20[1.30$ to 5.75$]$ & $<0.001$ \\
\hline First hematocrit (\%) $)^{a}$ & 575 & $33[29$ to 37$]$ & $33[29$ to 37$]$ & $33[28$ to 37$]$ & 0.424 \\
\hline Vasopressor within first $24 \mathrm{~h}$ & 619 & $438(70.8 \%)$ & $300(68.3 \%)$ & $138(76.7 \%)$ & 0.041 \\
\hline SOFA score at day 1 & 619 & 8 [6 to 10$]$ & $7[6$ to 9$]$ & $10[7$ to 13$]$ & $<0.001$ \\
\hline SAPS II score & 619 & $42[33$ to 54$]$ & 39 [31 to 47$]$ & $54[41$ to 68$]$ & $<0.001$ \\
\hline SAPS II score without age and renal components & 615 & 24 [18 to 32] & 23 [17 to 29$]$ & 29 [22 to 29] & $<0.001$ \\
\hline AKI (any severity) ${ }^{b}$ & 619 & $316(51.1 \%)$ & $203(46.2 \%)$ & $113(62.8 \%)$ & $<0.001$ \\
\hline AKI stage 1 & 619 & $122(19.7 \%)$ & $89(20.3 \%)$ & $33(18.3 \%)$ & 0.657 \\
\hline AKI stage 2 & 619 & $54(8.7 \%)$ & $40(9.1 \%)$ & $14(7.8 \%)$ & 0.641 \\
\hline AKI stage 3 & 619 & $140(22.6 \%)$ & $74(16.9 \%)$ & $66(36.7 \%)$ & $<0.001$ \\
\hline RRT for AKI during ICU stay & 619 & $101(16.3 \%)$ & $52(11.8 \%)$ & $49(27.2 \%)$ & $<0.001$ \\
\hline Mechanical ventilation during ICU stay & 619 & $404(65.3 \%)$ & $261(59.5 \%)$ & $143(79.4 \%)$ & $<0.001$ \\
\hline Fluid input on day 0 normalized to hours $(\mathrm{mL})^{c}$ & 619 & $247[173$ to 363$]$ & 238 [167 to 337] & $285[184$ to 417$]$ & 0.003 \\
\hline Cumulative balance \%/weight ${ }^{d}$ & 579 & $1.06[-2.75$ to 5.68$]$ & $0.15[-3.11$ to 4.31$]$ & $4.13[-2.20$ to 9.90$]$ & $<0.001$ \\
\hline ICU length of stay (days) & 618 & $4[2$ to 7$]$ & $4[2$ to 6$]$ & $5[2$ to 9$]$ & 0.022 \\
\hline
\end{tabular}

Categorical data reported as count (percentage) and continuous data as median [interquartile range, IQR]

ASO arteriosclerosis obliterans, COPD chronic obstructive pulmonal disease, ICU intensive care unit, NSAID non-steroidal anti-inflammatory drug, CNS central nervous system, GI gastrointestinal, SOFA sequential organ failure assessment considering all six organ systems, SAPSII Simplified Acute Physiology Score II, AKI acute kidney injury, $R R T$ renal replacement therapy

a First value measured within first $6 \mathrm{~h}$ from ICU admission

b All AKI patients

c For details please see "Methods"

d Cumulative fluid accumulation at discharge/on day 5 during ICU stay as a percentage of body weight 
$202-314 \mathrm{~mL} / \mathrm{h}$ in the 2 nd tertile, and $315-2824 \mathrm{~mL} / \mathrm{h}$ in the 3rd tertile. In all 619 patients VAP-1 levels were significantly lower in the lowest fluid administration tertile $(p<0.001)$ and in the middle tertile $(p=0.003)$ compared to the highest tertile, and IL- 6 levels higher $(p<0.001)$ in the highest fluid administration tertile compared to the middle or lowest tertile (Fig. 1, Table 2). SDC-1, Ang-2, or sTM levels did not differ between the fluid administration tertiles (Fig. 1, Table 2). Correlations between biomarkers are presented in Additional file 1: Table S2. All other biomarkers showed significant correlation with each other except (1) VAP-1 between SDC-1, (2) Ang-2 and STM between IL-6. The strongest correlation was between SDC-1 and sTM with rho of $0.406(p<0.001)$. IL- 6 and VAP-1 correlated negatively with each other (Additional file 1: Table S2). In linear regression models adjusted for IL-6, only VAP-1 was significantly associated with fluid administration on day 1 ( $\mathrm{B}[95 \% \mathrm{CI}]$ -0.139 [ -0.213 to -0.064$], p<0.001)$ and the cumulative fluid balance on day $5 / \mathrm{ICU}$ discharge $(B[95 \% \mathrm{CI}]$ -0.130 [ -0.209 to -0.052 ],$p=0.001$ ) (Additional file 1 : Tables S3 and S4). In the sequential samples subanalysis

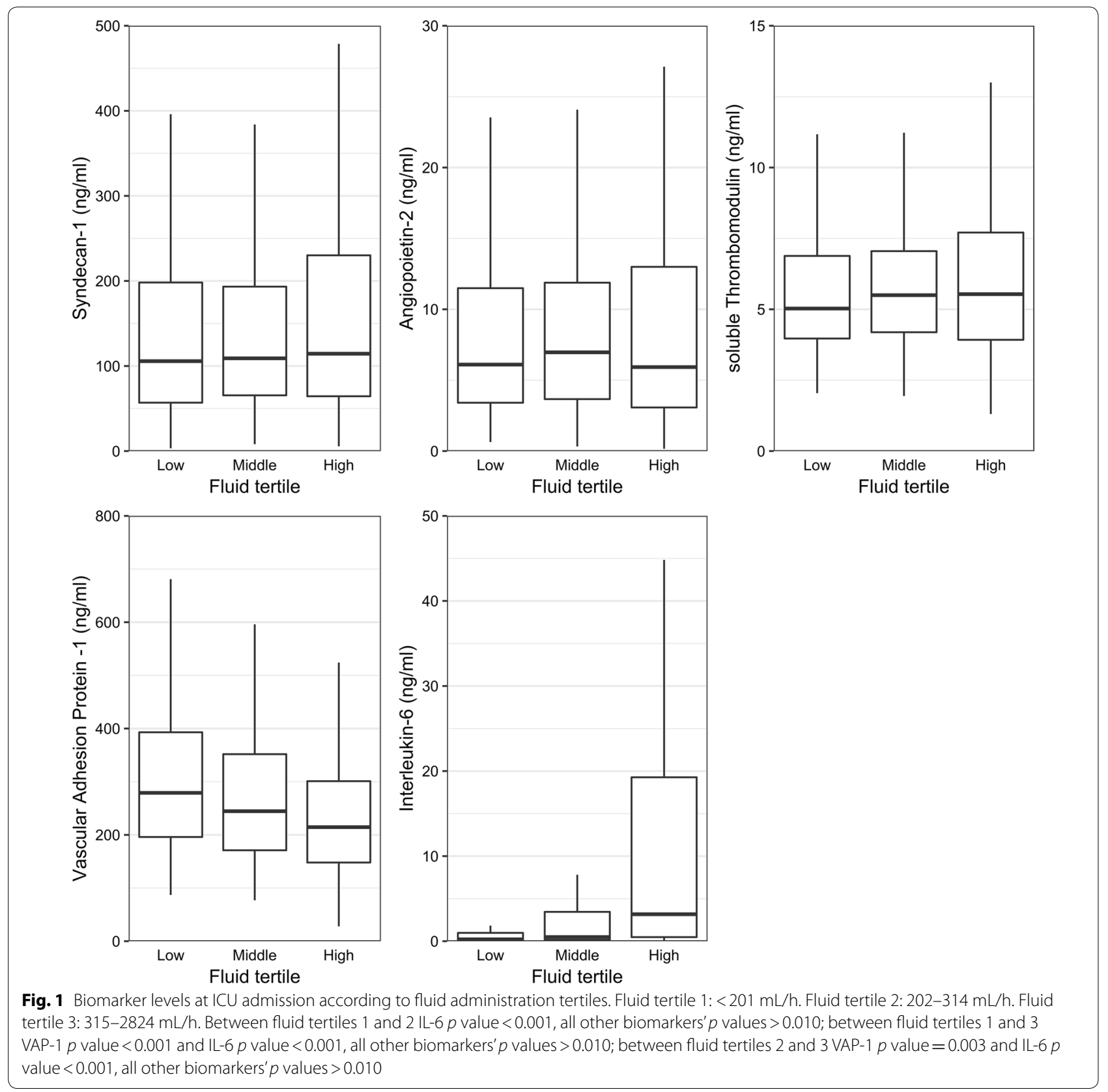


Table 2 Biomarker levels and fluid administration

\begin{tabular}{|c|c|c|c|c|}
\hline \multirow{2}{*}{$\begin{array}{l}\text { Biomarker level }(\mathrm{ng} / \mathrm{mL}) \text { at } \mathrm{O} \mathrm{h} \\
\text { (median [IQR]) }\end{array}$} & \multicolumn{4}{|l|}{ Fluid administration } \\
\hline & 1st tertile, $n=205(4-201 \mathrm{~mL} / \mathrm{h})$ & $\begin{array}{l}\text { 2nd tertile, } n=206 \\
(202-314 \mathrm{~mL} / \mathrm{h})\end{array}$ & $\begin{array}{l}\text { 3rd tertile, } n=208 \\
(315-2824 \mathrm{~mL} / \mathrm{h})\end{array}$ & $p$ value \\
\hline Syndecan-1 & $105.70[56.65-205.20]$ & $109.05[64.93-194.25]$ & $114.45[64.08-231.85]$ & 0.276 \\
\hline Angiopoietin-2 & $6.10[3.40-11.64]$ & $6.97[3.63-11.98]$ & $5.92[3.06-13.31]$ & 0.669 \\
\hline Soluble thrombomodulin & $5.03[3.94-6.93]$ & $5.50[4.18-7.07]$ & $5.53[3.91-7.72]$ & 0.282 \\
\hline Vascular adhesion protein-1 & 279.00 [195.50-395.50] & $244.50[170.75-355.25]$ & $214.50[148.00-305.00]$ & $<0.001$ \\
\hline Interleukin-6 & $0.22[0.07-1.00]$ & $0.49[0.16-0.36]$ & $3.17[0.45-19.51]$ & $<0.001$ \\
\hline
\end{tabular}

$I Q R$ interquartile range

including 40 patients with biomarkers measured every $12 \mathrm{~h}$ until $36 \mathrm{~h}$ available, SDC-1 values were increasing over time $(p<0.001)$, IL- 6 decreased $(p<0.001)$, and others did not show significant differences (Additional file 1: Figure S2).

\section{Biomarkers and organ failures and severity of sepsis} Patients whose SOFA scores decreased from first ICU day to ICU day $3(n=491)$ had significantly lower SDC-1 $(p=0.003)$ and IL-6 $(p=0.001)$ levels at ICU admission compared to those with worsening or stable SOFA scores $(n=127)$. Other biomarkers did not correlate with changes in SOFA scores.

\section{Biomarkers and AKI}

Altogether, 316 (51.1\%) patients had AKI. Of them, 189 $(59.8 \%)$ were diagnosed based on creatinine criterion only, 69 (21.8\%) based on urine output criterion only, 28 (8.9\%) had both creatinine and urine output criteria positive, and in 30 (9.5\%) patients commenced RRT before fulfilling other criteria. Of AKI patients, 204 (64.6\%) were admitted with AKI (AKI diagnosed 0-12 h from ICU admission), whereas 112 (35.4\%) were diagnosed more than $12 \mathrm{~h}$ from ICU admission. Of these ,112 $\mathrm{AKI}_{>12 \mathrm{~h}}$ patients $59(52.7 \%)$ had stage 1, $16(14.3 \%)$ had stage 2, and 37 (33.0\%) had stage 3 AKI according to the KDIGO criteria. All other biomarkers except VAP-1 were significantly higher in all AKI patients compared to non-AKI patients (Additional file 1: Table S5). Among $\mathrm{AKI}_{>12 \mathrm{~h}}$ patients SDC-1 and sTM were significantly higher compared to non-AKI patients (Table 3). After adjusting for possible confounders and IL-6 levels, sTM was significantly associated with $\mathrm{AKI}_{>12 \mathrm{~h}}$ (Table 4). Patients with the maximum biomarker summary score of 3 had an OR of 4.24 (95\% CI 1.64-10.96, $p=0.003$ ) for the development of AKI as compared to patients with the minimum biomarker summary score of 0 (Table 4).

\section{0-day mortality}

By day 90, 180 (29.1\%) patients were deceased. Non-survivors had higher SDC-1 and sTM levels than survivors (Table 5). After adjusting for multiple confounders, SDC1 , Ang2, and sTM were independently associated with an increased risk for 90-day mortality (Table 6). Altogether 65 patients had the maximum score of 3 in the biomarker summary score, and 35 (53.8\%) of them were deceased by day 90 . As compared to patients with the minimum biomarker summary score of 0 , patients with the maximum score had the adjusted odds of OR 5.61 (95\% CI 2.67$11.79, p<0.001$ ) for 90 -day mortality (Table 6 ).

\section{Discussion}

We found VAP-1 and IL-6 to be associated with the amount of administered fluid on the first ICU treatment day and other fluid balance-related variables; however, the other investigated markers did not differ according

Table 3 Biomarker levels in all patients and according to development of acute kidney injury

\begin{tabular}{lllll}
\hline $\begin{array}{l}\text { Biomarker level }(\mathbf{n g} / \mathbf{m L}) \text { at } \mathbf{~} \mathbf{h} \\
\text { (median [IQR]) }\end{array}$ & All patients $(\boldsymbol{n = 6 1 9 )}$ & No AKI $(\boldsymbol{n = 3 0 3})$ & AKI $>\mathbf{1 2} \mathbf{h}(\boldsymbol{n}=\mathbf{1 1 2})$ & $\boldsymbol{p}$ value \\
\hline Syndecan-1 & $109.00[62.30-215.40]$ & $91.40[55.30-157.30]$ & $125.25[67.60-232.68]$ & 0.004 \\
Angiopoietin-2 & $6.31[3.39-12.13]$ & $5.53[2.99-9.92]$ & $7.44[4.29-13.22]$ & 0.028 \\
Soluble Thrombomodulin & $5.30[4.02-7.13]$ & $4.61[3.69-5.97]$ & $5.84[4.37-7.94]$ & $<0.001$ \\
Vascular adhesion protein-1 & $241.00[171.00-340.00]$ & $255.00[177.00-356.00]$ & $241.50[170.75-340.00]$ & 0.889 \\
Interleukin-6 & $0.57[0.14-4.74]$ & $0.36[0.12-3.06]$ & $0.83[0.17-5.10]$ & 0.011 \\
\hline
\end{tabular}

AKI > $12 \mathrm{~h}$; AKI diagnosed over $12 \mathrm{~h}$ from ICU admission to day 5 or ICU discharge, if earlier 
Table 4 Unadjusted and adjusted single and multivariable biomarker logistic regression models for the development of acute kidney injury

\begin{tabular}{|c|c|c|c|c|c|c|}
\hline \multicolumn{7}{|l|}{ Single biomarker models } \\
\hline Biomarker & Unadjusted OR (95\% CI) & $p$ value & IL-6 adjusted ${ }^{\mathrm{a}}$ OR $(95 \% \mathrm{Cl})$ & $p$ value & $\begin{array}{l}\text { Multivariable } \\
\text { adjusted }^{\text {b }} \text { OR ( } 95 \% \\
\text { Cl) }\end{array}$ & $p$ value \\
\hline Log Angiopoietin-2 & $2.66(1.53-4.63)^{c}$ & 0.001 & $2.40(1.37-4.21)$ & 0.002 & $1.96(1.05-3.66)$ & 0.034 \\
\hline Log soluble thrombomodulin & $30.72(8.37-112.67)$ & $<0.001$ & $29.55(7.87-110.89)$ & $<0.001$ & $12.71(2.96-54.67)$ & 0.001 \\
\hline Log Syndecan-1 & $1.98(1.15-3.42)$ & 0.014 & $1.90(1.10-3.30)$ & 0.022 & $1.49(0.80-2.77)$ & 0.212 \\
\hline Log vascular adhesion protein 1 & $1.07(0.40-2.88)$ & 0.891 & $1.66(0.59-4.71)$ & 0.340 & $0.93(0.28-3.07)$ & 0.907 \\
\hline \multicolumn{7}{|l|}{ Biomarker summary score $^{c}$} \\
\hline $\begin{array}{l}\text { Score-patients with } \mathrm{AKI} \text { no/ } \\
\text { total to }(\%)\end{array}$ & Unadjusted OR (95\% Cl) & $p$ value & IL-6 adjusted ${ }^{\mathrm{a}}$ OR $(95 \% \mathrm{CI})$ & $p$ value & $\begin{array}{l}\text { Multivariable } \\
\text { adjusted }^{\text {b }} \text { OR ( } 95 \% \\
\text { Cl) }\end{array}$ & $p$ value \\
\hline $0-36 / 195(18.5 \%)$ & Reference & - & Reference & - & Reference & - \\
\hline $1-32 / 121(26.4 \%)$ & $1.59(0.92-2.73)$ & 0.095 & $1.47(0.85-2.54)$ & 0.169 & $1.50(0.83-2.70)$ & 0.176 \\
\hline 2-28/72 (38.9\%) & $2.81(1.55-5.10)$ & 0.001 & $2.73(1.49-4.97)$ & 0.001 & $2.11(1.09-4.11)$ & 0.027 \\
\hline $3-16 / 27(59.3 \%)$ & $6.42(2.75-15.01)$ & $<0.001$ & $5.96(2.53-14.03)$ & $<0.001$ & $4.24(1.64-10.96)$ & 0.003 \\
\hline
\end{tabular}

Hosmer-Lemeshow test non-significant in all analyses

AKI acute kidney injury, IL-6 interleukin-6

a Adjusted for log-transformed interleukin- 6 value at ICU admission

b Adjusted for age, sex, body mass index, pre-existing chronic kidney disease, pre-existing diabetes mellitus, presence of urinary tract infection, presence of skin or soft tissue infection, Simplified Acute Physiology Score (SAPS) II without points for age and renal components, need for vasoactive medication within first $24 \mathrm{~h}$, first lactate in ICU, log-transformed interleukin-6 value at ICU admission. Total number of patients in the model was 415 . ${ }^{\mathrm{b}}$ Including Angiopoietin-2, soluble thrombomodulin and Syndecan-1

c An example of the interpretation of the OR of log-transformed biomarkers: the OR for development for AKI for Log Angiopoietin-2 is 2.66, so when untransformed Angiopoietin-2 levels grow by a factor of 10, the odds for AKI increase by a factor of 2.66

Table 5 Biomarker levels in all patients and according to 90-day mortality

\begin{tabular}{|c|c|c|c|c|}
\hline $\begin{array}{l}\text { Biomarker level }(\mathrm{ng} / \mathrm{mL}) \text { at } 0 \mathrm{~h} \\
\text { (median [IQR]) }\end{array}$ & All patients $(n=619)$ & 90-day survivors $(n=439)$ & 90-day non-survivors $(n=180)$ & $p$ value \\
\hline Syndecan-1 & $109.00[62.30-215.40]$ & $98.10[58.40-180.00]$ & $157.05[72.50-310.80]$ & $<0.001$ \\
\hline Angiopoietin-2 & $6.31[3.39-12.13]$ & $5.92[3.30-11.26]$ & $7.60[4.01-17.44]$ & 0.013 \\
\hline Soluble thrombomodulin & $5.30[4.02-7.13]$ & $5.08[3.88-6.81]$ & $5.90[4.37-8.19]$ & $<0.001$ \\
\hline Vascular adhesion protein-1 & $241.00[171.00-340.00]$ & 239.00 [171.00-339.00] & 253.00 [168.25-340.00] & 0.676 \\
\hline Interleukin-6 & $0.57[0.14-4.74]$ & $0.54[0.13-4.25]$ & $0.67[0.15-6.51]$ & 0.147 \\
\hline
\end{tabular}

to fluid administration. Only sTM remained associated with the development of AKI after adjusting for known confounders. Finally, Ang-2, SDC-1, and sTM were associated with an increased risk for 90-day mortality, also after adjustments. Our results demonstrate that injury to glycocalyx and endothelium present at ICU admission is associated with an increased risk for AKI and mortality.

We observed roughly comparable plasma biomarker levels to previous studies [8, 22, 23]. Previously, Ang-2 has been shown to correlate with the first 6-h balance, but not with the 24-h balance [24]. Our results corroborate this finding. However, we did not find significant differences in SDC-1 levels in terms of fluid administration or balance, in contrast with a previous study that found SDC-1 to be associated with fluid balance over the first $24 \mathrm{~h}$ [25]. That study measured SDC-1 levels on the second ICU day, whereas we obtained samples right after ICU admission. A novel finding in our study was the association of higher IL-6 and lower VAP-1 levels with higher amount of received fluids. As more severely ill patients have higher IL-6 levels [26], and typically receive also more fluids [27], the finding regarding IL-6 was to be expected. The finding regarding VAP-1 is surprising, as one would have expected higher VAP-1 levels with higher 
Table 6 Unadjusted and adjusted single and multivariable biomarker models for $\mathbf{9 0}$-day mortality

\begin{tabular}{|c|c|c|c|c|c|c|}
\hline \multicolumn{7}{|l|}{ Single biomarker models } \\
\hline Biomarker & Unadjusted OR (95\% Cl) & $p$ value & IL-6 adjusted ${ }^{\mathrm{a}}$ OR $(95 \% \mathrm{Cl})$ & $p$ value & $\begin{array}{l}\text { Multivariable } \\
\text { adjusted }^{\text {b }} \text { OR (95\% } \\
\text { CI) }\end{array}$ & $p$ value \\
\hline Log Angiopoietin-2 & $1.69(1.12-2.55)$ & 0.012 & $1.57(1.03-2.38)$ & 0.035 & $2.47(1.44-4.14)$ & 0.001 \\
\hline Log soluble thrombomodulin & $2.36(1.58-3.53)$ & $<0.001$ & $2.27(1.52-3.40)$ & $<0.001$ & $7.35(2.29-23.57)$ & 0.001 \\
\hline Log Syndecan-1 & $6.45(2.58-16.09)$ & $<0.001$ & $5.94(2.36-14.91)$ & $<0.001$ & $2.13(1.31-3.49)$ & 0.002 \\
\hline Log vascular adhesion protein 1 & $0.99(0.47-2.09)$ & 0.980 & $1.26(0.58-2.75)$ & 0.565 & $2.02(0.73-5.57)$ & 0.177 \\
\hline \multicolumn{7}{|l|}{ Biomarker summary score ${ }^{a}$} \\
\hline $\begin{array}{l}\text { Score-90-day non-survivors } \\
\text { no/total to }(\%)\end{array}$ & Unadjusted OR (95\% Cl) & $p$ value & IL-6 adjusted ${ }^{\mathrm{a}}$ OR $(95 \% \mathrm{CI})$ & $p$ value & $\begin{array}{l}\text { Multivariable } \\
\text { adjusted }^{\text {b }} \text { OR (95\% } \\
\text { CI) }\end{array}$ & $p$ value \\
\hline $0-57 / 249(22.9 \%)$ & Reference & - & Reference & - & Reference & - \\
\hline $1-49 / 187(26.2 \%)$ & $1.20(0.77-1.86)$ & 0.425 & $1.17(0.75-1.81)$ & 0.500 & $1.19(0.70-2.01)$ & 0.530 \\
\hline $2-39 / 118(33.1 \%)$ & $1.66(1.03-2.70)$ & 0.040 & $1.60(0.98-2.61)$ & 0.058 & $1.93(1.07-3.47)$ & 0.029 \\
\hline $3-35 / 65(53.8 \%)$ & $3.93(2.22-6.95)$ & $<0.001$ & $3.69(2.07-6.57)$ & $<0.001$ & $5.61(2.67-11.79)$ & $<0.001$ \\
\hline \multicolumn{7}{|c|}{ Hosmer-Lemeshow test non-significant in all analyses } \\
\hline \multicolumn{7}{|c|}{ IL-6 interleukin-6 } \\
\hline \multicolumn{7}{|c|}{ adjusted for log-transformed interleukin- 6 value at ICU admission } \\
\hline \multicolumn{7}{|c|}{$\begin{array}{l}\text { Adjusted for age, sex, body mass index, pre-existing arteriosclerosis, chronic heart failure, chronic kidney disease, diabetes mellitus, chronic corticosteroid use, } \\
\text { operative admission, skin or soft tissue infection, central nervous system infection, other infection source, need for vasoactive medication within first } 24 \text { h, Simplified } \\
\text { Acute Physiology Score (SAPS) II without points for age and renal components, first lactate in ICU, acute kidney injury within first } 5 \text { days in the ICU, fluid accumulation } \\
\text { percentage of baseline weight within first } 5 \text { days in ICU, mechanical ventilation during ICU stay, and log-transformed interleukin- } 6 \text { value at ICU admission. Total } \\
\text { number of patients in the model was } 619\end{array}$} \\
\hline
\end{tabular}

fluid administration and severity of illness. However, the transmembrane form of VAP-1 facilitates leukocyte rolling and transmigration, whereas the soluble form acts as a primary serum amine oxidase [28]. Possibly, in the most severely ill septic patients, the shedding of transmembrane form of VAP-1 into soluble form is reduced due to greater needs of the transmembrane form. Moreover, the plasma levels do not necessarily reflect the tissue levels of a biomarker. Finally, dilution of VAP-1 with increasing fluid balance cannot be excluded.

sTM was independently associated with the development of AKI, as in a recent retrospective observational study among 514 septic patients [29] and a multicenter prospective observational study among 80 ICU patients [30]. Moreover, we demonstrated that an increase in sTM levels occurred already before AKI onset, unlike in the largest previous study [29]. Interestingly, we found Ang-2 to be significantly associated with AKI in the univariate analysis but not in the adjusted model. A previous study reported an unadjusted association of AKI defined by the KDIGO creatinine criterion and Ang-2 levels [24]. Higher SDC-1 values have been previously observed to be associated with AKI in a study among 175 septic patients [31]. Albeit the SDC-1 levels in this study were higher among $\mathrm{AKI}_{>12 \mathrm{~h}}$ patients, $\mathrm{SDC}-1$ was not independently associated with AKI.

Our study corroborates previous results on the associations between higher SDC-1, Ang-2 and sTM plasma levels and the severity of critical illness and mortality [9, $22,25,31-33]$. A multicenter trial in acute respiratory distress syndrome (ARDS) patients reported a positive correlation between sTM plasma levels and mortality, but found no difference in sTM levels between conservative and liberal fluid management groups [34]. Moreover, a recent study comparing early goal-directed therapy, standard therapy, and protocolized therapy found no difference in endothelial injury biomarkers including sTM and Ang-2 between the treatment arms, but higher Ang-2 and STM plasma levels were associated with 60-day mortality [32]. We found an independent association between Ang-2, sTM, and SDC-1 and 90-day mortality. Moreover, patients who had high levels of all these three markers had a fivefold adjusted OR for 90-day mortality compared to those in whom all these markers were low.

Given the multiple roles of the glycocalyx and endothelium in regulating vascular permeability and leukocyte adhesion [1-4], our results on increased mortality are biologically plausible. A recent animal study 
in experimental sepsis found fluid resuscitation (compared to no resuscitation) to increase atrial natriuretic peptide (ANP) levels and lead to glycocalyx injury [35]. Furthermore, fluid resuscitation group exhibited higher vasopressor requirements, potentially due to glycocalyx damage [35]. Additionally, hypervolemia has been found to increase glycocalyx shedding in an experimental volume loading study in surgical patients [36]. Taken together, these data suggest that some of the typical interventions used in sepsis resuscitation may aggravate glycocalyx and endothelial injury. Our results add to the increasing body of evidence highlighting the importance of endothelial and glycocalyx injury in the pathway of adverse outcomes and call for studies assessing novel means in avoiding and alleviating injury to endothelium and glycocalyx.

Our study has some strengths and limitations. This was a post hoc study from a large prospective multicenter study with good generalizability to other critically ill septic patient cohorts. Moreover, we used the full set of KDIGO AKI criteria, and collected detailed and comprehensive data about clinical variables and risk factors for AKI. Most of the previous studies have used only the creatinine criterion for AKI [22-24, 31]. As a limitation, first, our study collected data about fluid administration and balance in 24-h blocks, which may not be granular enough to distinguish the fluid resuscitation phase. However, we extracted the fluid administration data of 44 patients in 12-h blocks from the ICU data management system as a sensitivity analysis, and found it to correlate well with the ICU admission day fluid administration normalized to the duration of observation period. Second, we did not have data regarding the pre-ICU fluid therapy, which may have affected plasma biomarker levels at ICU admission and may explain why we could not show a connection between other biomarkers than VAP-1 and IL-6 and fluid load. However, some studies have suffered from the same limitation [25]. Third, we had to exclude 36 deceased patients from the analysis because of absent consent. Nevertheless, percentage of these patients of the cohort was low (5.5\%), and thus, unlikely to cause significant bias. Fourth, this study was observational and had no protocol concerning hemodynamic monitoring or fluid responsiveness. Therefore, hemodynamic monitoring was performed and fluids were administered according to the treating clinician and standards of each participating ICU following the Surviving Sepsis Guidelines [13] in place that time. Fifth, we defined sepsis according to the American College of Chest Physicians/Society of Critical Care Medicine (ACCP/SCCM) definition [14]. Due to the structure of data collection, classifying patients retrospectively according to the sepsis-3 definition was not possible. Sixth, fluid balance was calculated with inputs and outputs since weighting of all study participants was not possible. However, it is not obvious that regular body weight measures would be more precise to estimate fluid balance than fluid balance calculations [37]. Seventh, we used data-driven approach supplemented with clinical discretion in selecting confounders for the logistic regression analyses, albeit a propensity score analysis might have been able to mitigate confounding better [38]. Finally, some unknown confounders might have been missing.

\section{Conclusions}

We found VAP-1 and IL-6, but not the other markers, to be associated with fluid administration on the first ICU day. Supporting previous results, sTM was independently associated with the development of AKI. Finally, Ang-2, sTM, and SDC-1 were independently associated with an increased risk for 90-day mortality. These findings support the importance of endothelial injury in the pathophysiology of sepsis-associated AKI and highlight the role of the glycocalyx and endothelium in the pathway of adverse outcomes.

\section{Supplementary information}

Supplementary information accompanies this paper at https://doi. org/10.1186/s13613-019-0575-y.

Additional file 1: Figure S1. Flow chart. Table S1. Biomarker levels and chronic diseases. Figure S2. Sequential samples subanalysis including 40 patients with biomarkers measured every $12 \mathrm{hrs}$ until 36 hrs. Table S2. Correlation between biomarkers. Table S3. Multivariable linear regression models predicting log Fluid input on Day 0 normalized to hours. Table S4. Multivariable linear regression models predicting Cumulative balance \%/ weight. TableS5. Biomarker levels and acute kidney injury.

\section{Abbreviations}

AKl: acute kidney injury; $\mathrm{AKI}_{>12} \mathrm{~h}$ : development of $\mathrm{AKI}$ after $12 \mathrm{~h}$ from admission; Ang-2: angiopoietin-2; ANP: atrial natriuretic peptide; ICU: intensive care unit; IL-6: interleukin-6; KDIGO: Kidney Disease Improving Global Outcomes; SAPS II: Simplified Acute Physiology Score II; SDC-1: syndecan-1; SOFA: sequential organ failure assessment; sTM: soluble thrombomodulin; VAP-1: vascular adhesion protein-1.

\section{Acknowledgements}

We acknowledge the assistance of Anna But biostatistician, University of Helsinki, for biostatistic consulting.

\section{Authors' contributions}

VP and STV conceived the study. VP, AK, OI, TAK, SB, and the members of the FINNAKI study group collected the data. PL provided facilities for laboratory analyses and supervised the laboratory analyses. NI analyzed the data with help from STV and SJ and drafted the manuscript. SJ performed linear regression analyses. STV and VP helped to interpret the results and write the manuscript. PL, AK, OI, SJ, TAK, and SB critically commented the manuscript. All authors read and approved the final manuscript.

\section{Funding}

The study has been supported by the Academy of Finland, the Sigrid Juselius Foundation, Päivikki and Sakari Sohlberg Foundation, and Institutional 
Grants from the Helsinki University Hospital (TYH2013343, TYH2016243, TYH 2017241). STV has received a Fellowship Grant from the Sigrid Juselius Foundation and funding for Clinical Researchers (317061) from the Academy of Finland.

\section{Availability of data and materials}

The datasets analyzed during this study are available from the corresponding author for a reasonable request.

\section{Ethics approval and consent to participate}

The Ethics Committee of the Department of Surgery at the Helsinki University Hospital gave nationwide approval for the study (reference number: 18/13/03/02/2010) and accepted the use of deferred consent from the patient or next of kin with written informed consent obtained as soon as possible.

\section{Consent for publication}

Not applicable.

\section{Competing interests}

The authors declare that they have no competing interests.

\section{Author details}

${ }^{1}$ Department of Anesthesia and Intensive Care, Central Finland Central Hospital, Central Finland Health Care District, Keskussairaalantie 19 M rak 2krs, 40620 Jyväskylä, Finland. ${ }^{2}$ Division of Intensive Care Medicine, Department of Anesthesiology, Intensive Care and Pain Medicine, University of Helsinki and Helsinki University Hospital, Helsinki, Finland. ${ }^{3}$ Department of Clinical Chemistry, University of Helsinki and Helsinki University Hospital, Helsinki, Finland. ${ }^{4}$ Minerva Foundation Institute for Medical Research, Helsinki, Finland. ${ }^{5}$ Department of Intensive Care, University of Tampere and Tampere University Hospital, Tampere, Finland. ${ }^{6}$ Department on Intensive Care Medicine, Kuopio University Hospital, Kuopio, Finland. ${ }^{7}$ Department of Anaesthesia and Intensive Care Medicine, Turku University Hospital, Turku, Finland. ${ }^{8}$ Research Group of Surgery, Anesthesiology and Intensive Care Medicine and Medical Research Center, Oulu University Hospital, Oulu University, Oulu, Finland. ${ }^{9}$ Department of Intensive Care, Austin Hospital, Melbourne, Australia.

Received: 15 May 2019 Accepted: 29 August 2019

Published online: 11 September 2019

\section{References}

1. Alphonsus CS, Rodseth RN. The endothelial glycocalyx: a review of the vascular barrier. Anaesthesia. 2014;69(7):777-84.

2. Pries AR, Secomb TW, Gaehtgens P. The endothelial surface layer. Pflugers Arch. 2000;440(5):653-66.

3. Reitsma S, Slaaf DW, Vink H, van Zandvoort MAMJ, Oude Egbrink MGA. The endothelial glycocalyx: composition, functions, and visualization. Pflugers Arch. 2007;454(3):345-59.

4. Chelazzi C, Villa G, Mancinelli P, De Gaudio AR, Adembri C. Glycocalyx and sepsis-induced alterations in vascular permeability. Crit Care Lond Engl. 2015;28(19):26

5. Chignalia AZ, Yetimakman F, Christiaans SC, Unal S, Bayrakci B, Wagener BM, et al. The glycocalyx and trauma: a review. Shock Augusta Ga. 2016;45(4):338-48.

6. Johansson PI, Stensballe J, Ostrowski SR. Shock induced endotheliopathy (SHINE) in acute critical illness - a unifying pathophysiologic mechanism. Crit Care Lond Engl. 2017;21(1):25.

7. Martin L, Koczera P, Zechendorf E, Schuerholz T. The endothelial glycocalyx: new diagnostic and therapeutic approaches in sepsis. Biomed Res Int 2016;2016:3758278.

8. Sallisalmi M, Tenhunen J, Yang R, Oksala N, Pettilä V. Vascular adhesion protein-1 and syndecan-1 in septic shock. Acta Anaesthesiol Scand. 2012;56(3):316-22.

9. Xing K, Murthy S, Liles WC, Singh JM. Clinical utility of biomarkers of endothelial activation in sepsis-a systematic review. Crit Care Lond Engl. 2012;16(1):R7

10. Chao T-H, Tsai W-C, Chen J-Y, Liu P-Y, Chung H-C, Tseng S-Y, et al. Soluble thrombomodulin is a paracrine anti-apoptotic factor for vascular endothelial protection. Int J Cardiol. 2014;172(2):340-9.
11. Orbegozo D, Rahmania L, Irazabal M, Mendoza M, Annoni F, De Backer $D$, et al. Endocan as an early biomarker of severity in patients with acute respiratory distress syndrome. Ann Intensive Care. 2017;7(1):93.

12. Nisula S, Kaukonen K-M, Vaara ST, Korhonen A-M, Poukkanen M, Karlsson S, et al. Incidence, risk factors and 90-day mortality of patients with acute kidney injury in Finnish intensive care units: the FINNAKI study. Intensive Care Med. 2013;39(3):420-8.

13. Dellinger RP, Levy MM, Carlet JM, Bion J, Parker MM, Jaeschke $\mathrm{R}$, et al. Surviving Sepsis Campaign: international guidelines for management of severe sepsis and septic shock: 2008. Crit Care Med. 2008;36(1):296-327.

14. Bone RC, Balk RA, Cerra FB, Dellinger RP, Fein AM, Knaus WA, et al. Definitions for sepsis and organ failure and guidelines for the use of innovative therapies in sepsis. The ACCP/SCCM Consensus Conference Committee. American College of Chest Physicians/Society of Critical Care Medicine. Chest. 1992;101(6):1644-55.

15. Kellum JA, Lameire N, Aspelin P, Barsoum RS, Burdmann EA, Goldstein $\mathrm{SL}$, et al. Kidney disease: improving global outcomes (KDIGO) acute kidney injury work group. KDIGO clinical practice guideline for acute kidney injury. Kidney Int Suppl. 2012;2(1):1-138.

16. Levey AS, Coresh J, Balk E, Kausz AT, Levin A, Steffes MW, et al. National Kidney Foundation practice guidelines for chronic kidney disease: evaluation, classification, and stratification. Ann Intern Med. 2003;139(2):137-47.

17. Vaara ST, Hollmén M, Korhonen A-M, Maksimow M, Ala-Kokko T, Salmi M, et al. Soluble CD73 in critically ill septic patients-data from the prospective FINNAKI Study. PLOS ONE. 2016;11:10.

18. Stroeder J, Bomberg H, Wagenpfeil S, Buecker A, Schaefers H-J, Katoh $M$, et al. Presepsin and inflammatory markers correlate with occurrence and severity of nonocclusive mesenteric ischemia after cardiovascular surgery. Crit Care Med. 2018;46(6):e575-83.

19. Leslie K, Edgley C, Lee AC-Y, Sellar A, Sgroi J, Toh R. Reporting of sex and gender in human studies published in anaesthesia journals. $\mathrm{Br} J$ Anaesth. 2018;120(5):1128-30.

20. Budde H, Papert S, Maas J-H, Reichardt HM, Wulf G, Hasenkamp J, et al. Prediction of graft-versus-host disease: a biomarker panel based on lymphocytes and cytokines. Ann Hematol. 2017;96(7):1127-33.

21. Osborn TM, Phillips G, Lemeshow S, Townsend S, Schorr CA, Levy $M M$, et al. Sepsis severity score: an internationally derived scoring system from the surviving sepsis campaign database. Crit Care Med. 2014;42(9):1969-76.

22. Johansen ME, Johansson PI, Ostrowski SR, Bestle MH, Hein L, Jensen ALG, et al. Profound endothelial damage predicts impending organ failure and death in sepsis. Semin Thromb Hemost. 2015;41(1):16-25.

23. Robinson-Cohen C, Katz R, Price BL, Harju-Baker S, Mikacenic C, Himmelfarb J, et al. Association of markers of endothelial dysregulation Ang1 and Ang2 with acute kidney injury in critically ill patients. Crit Care Lond Engl. 2016;20(1):207.

24. Fisher J, Douglas JJ, Linder A, Boyd JH, Walley KR, Russell JA. Elevated plasma angiopoietin-2 levels are associated with fluid overload, organ dysfunction, and mortality in human septic shock. Crit Care Med. 2016;44(11):2018-27.

25. Murphy LS, Wickersham N, McNeil JB, Shaver CM, May AK, Bastarache JA, et al. Endothelial glycocalyx degradation is more severe in patients with non-pulmonary sepsis compared to pulmonary sepsis and associates with risk of ARDS and other organ dysfunction. Ann Intensive Care. 2017;7(1):102.

26. Ríos-Toro J-J, Márquez-Coello M, García-Álvarez J-M, Martín-Aspas A, Rivera-Fernández R, Sáez de Benito A, et al. Soluble membrane receptors, interleukin 6 , procalcitonin and $C$ reactive protein as prognostic markers in patients with severe sepsis and septic shock. PLOS ONE. 2017;12(4):e0175254.

27. Tigabu BM, Davari M, Kebriaeezadeh A, Mojtahedzadeh M. Fluid volume, fluid balance and patient outcome in severe sepsis and septic shock: a systematic review. J Crit Care. 2018;20(48):153-9.

28. Pannecoeck R, Serruys D, Benmeridja L, Delanghe JR, van Geel N, Speeckaert $\mathrm{R}$, et al. Vascular adhesion protein-1: role in human pathology and application as a biomarker. Crit Rev Clin Lab Sci. 2015;52(6):284-300.

29. Katayama S, Nunomiya S, Koyama K, Wada M, Koinuma T, Goto Y, et al. Markers of acute kidney injury in patients with sepsis: the role of soluble thrombomodulin. Crit Care Lond Engl. 2017;21(1):229. 
30. Bouchard J, Malhotra R, Shah S, Kao Y-T, Vaida F, Gupta A, et al. Levels of protein $C$ and soluble thrombomodulin in critically ill patients with acute kidney injury: a multicenter prospective observational study. PLOS ONE. 2015;10(3):e0120770.

31. Puskarich MA, Cornelius DC, Tharp J, Nandi U, Jones AE. Plasma syndecan-1 levels identify a cohort of patients with severe sepsis at high risk for intubation after large-volume intravenous fluid resuscitation. J Crit Care. 2016;36:125-9.

32. Hou PC, Filbin MR, Wang H, Ngo L, Huang DT, Aird WC, et al. Endothelial permeability and hemostasis in septic shock: results from the ProCESS Trial. Chest. 2017;152(1):22-31.

33. de Neves FM, Meneses GC, Sousa NEA, de Menezes RRPPB, Parahyba MC, Martins AMC, et al. Syndecan-1 in acute decompensated heart failureassociation with renal function and mortality. Circ J Off J Jpn Circ Soc. 2015;79(7):1511-9.

34. Sapru A, Calfee CS, Liu KD, Kangelaris K, Hansen H, Pawlikowska L, et al. Plasma soluble thrombomodulin levels are associated with mortality in the acute respiratory distress syndrome. Intensive Care Med. 2015;41(3):470-8.
35. Byrne L, Obonyo NG, Diab SD, Dunster KR, Passmore MR, Boon A-C, et al. Unintended consequences; fluid resuscitation worsens shock in an ovine model of endotoxemia. Am J Respir Crit Care Med. 2018;198:1043-54.

36. Chappell D, Bruegger D, Potzel J, Jacob M, Brettner F, Vogeser M, et al. Hypervolemia increases release of atrial natriuretic peptide and shedding of the endothelial glycocalyx. Crit Care Lond Engl. 2014;18(5):538.

37. Schneider AG, Baldwin I, Freitag E, Glassford N, Bellomo R. Estimation of fluid status changes in critically ill patients: fluid balance chart or electronic bed weight? J Crit Care. 2012;27(6):745.e7-12.

38. Ranstam J, Cook JA. Causal relationship and confounding in statistical models. Br J Surg. 2016;103(11):1445-6.

\section{Publisher's Note}

Springer Nature remains neutral with regard to jurisdictional claims in published maps and institutional affiliations.

\section{Submit your manuscript to a SpringerOpen ${ }^{\circ}$ journal and benefit from:}

- Convenient online submission

- Rigorous peer review

- Open access: articles freely available online

- High visibility within the field

- Retaining the copyright to your article

Submit your next manuscript at $\mathbf{s p r i n g e r o p e n . c o m ~}$ 